\title{
Desplazamiento accidental de la tercera molar inferior impactada al espacio faríngeo lateral
}

Accidental displacement of the third lower molar impacted towards the lateral pharyngeal space

\section{Resumen}

Se reporta accidente inusual de desplazamiento de tercera molar inferior al espacio faríngeo lateral izquierdo, en paciente femenino de 21 ańos de edad, localizado mediante el examen tomográfico. Para la remoción de la pieza dentaria, se utilizó anestesia local (lidocaína al $2 \%$ con epinefrina 1:100 000), se realizó incisión desde distal de la pieza 3,7 continuando por el reborde alveolar hasta la apófisis coronoides y mediante disección roma, se logró encontrar la pieza dentaria, la cual fue prensada y removida con pinza hemostática. Se concluye que debe realizarse una valoración de la posible complejidad en la exodoncia de las terceras molares y derivar al especialista los casos de moderada y alta complejidad para evitar complicaciones.

Palabras clave: Tercer molar retenida, complicaciones, desplazamiento, espacio faríngeo lateral.

\begin{abstract}
An unusual accident of displacement of the third lower molar towards the left lateral pharyngeal space was reported in a 21-year old female patient, located through the tomographic exam. In order to remove the dental piece, local anesthesia was used ( $2 \%$ of lidocaine with epinephrine 1:100 000). An incision was made from the distal of the 3,7 piece continuing by the alveolar ridge up to the coronoid process, and through a blunt dissection the dental piece was found, the same that was grasped and then removed with haemostatic clamps. It was concluded that valuation of the potential complexity regarding the dental extraction of the third molars must be made; and that moderate and high-complexity cases must be derived to the specialist to avoid complications.
\end{abstract}

Key words:: Third molar impacted, lateral pharyngeal space.

\section{Introducción}

La exodoncia de las terceras molares es la intervención quirúrgica más frecuente en Cirugía Máxilo Facial y continúa siendo una práctica profiláctica universal. Algunos reportes estiman la remoción de terceros molares retenidos, sin justificación clínica, entre el $18 \%$ y el $50,7 \%$. La cirugía profiláctica preconiza la necesidad de minimizar el riesgo de desarrollo de quistes, tumores, fractura a nivel del ángulo mandibular, pericoronaritis y reabsorción radicular del segundo molar. ${ }^{1,2}$

Una complicación puede definirse como un evento desagradable que ocurre durante o después de una intervención quirúrgica. Si este suceso no es advertido, no es tratado o su tratamiento es incorrecto provocará serias consecuencias o secuelas al paciente. Las complicaciones durante la exodoncia del tercer molar son, básicamente, las mismas que pueden acontecer durante la intervención quirúrgica de cualquier otra pieza dentaria; pero por la comple- jidad de la técnica de exodoncia de un diente incluido o retenido y por las relaciones anatómicas que presenta el tercer molar, son más frecuentes, complicadas y tendrán características peculiares. ${ }^{2}$

Otros autores como Sacot N y Ferrería $\mathrm{J}$, afirman que no se puede denominar accidentes a los casos donde se complica la cirugía, ya que se estaría transformando el hecho en un acontecimiento permisivo. El término accidente sería válido para aquellos acontecimientos desagradables que se encuentran alejados del gobierno (previsión o control) del profesional. ${ }^{3}$

Dentro de las complicaciones más frecuentes tenemos: alveolitis (29,6\%), celulitis facial posquirúrgica $(22,7 \%)$, hemorragia $(18,2 \%)$ y trismo mandibular $(13,7 \%) .{ }^{4}$ Otras complicaciones más severas, pero menos frecuentes, son: neumotórax, enfisema subcutáneo, retrofaríngeo y mediastinal, así como el desplazamiento accidental hacia diferentes espacios anatómicos. ${ }^{1,5,6}$ Cabe destacar que la incidencia de dichas complicaciones es baja y se mantiene

\section{Queneth Del Águila del Castillo' Pablo Moncada Ameghino² Henry Vilcapoma Guerra ${ }^{3}$}

Profesor de la Especialidad de Cirugía Buco Máxilo Facial de la Universidad Nacional Mayor de San Marcos, Jefe del Servicio de Medicina Oral y Cirugía Máxilo Facial del Hospital Central FAP.

2 Servicio de Medicina Oral y Cirugía Máxilo Facial del Hospital Central FAP, Profesor de la Universidad Nacional Federico Villarreal.

${ }^{3}$ Cirujano Dentista egresado de la Facultad de Odontología de la UNMSM.

Correspondencia:

C.D. Henry Vilcapoma Guerra Av. José Santos Chocano 338, Urb. Villa Los Angeles, Los Olivos.

Correo: henry_vilcapoma@hotmail.com

(511) 9-8963-6863 baja cuando el tiempo del cirujano dentista como especialista aumenta. ${ }^{7}$

El desplazamiento íntegro de una tercera molar impactada, algún fragmento de raíz o corona son complicaciones que ocurren raramente durante una exodoncia. A pesar que dichas complicaciones son conocidas, los casos reportados al respecto son escasos. ${ }^{8-10}$

Se debe efectuar el diagnóstico de las retenciones y determinar el grado de dificultad en su tratamiento. El grado de dificultad depende de muchos factores como la posición anatómica, profundidad ósea, relación con piezas dentarias contiguas, forma, tamaño y dirección de las raíces, cercanía con elementos nobles (dentario inferior o seno maxilar), patología asociada (quistes, tumores). Sin embargo, teniendo todo esto en cuenta, pueden ocurrir complicaciones. ${ }^{11}$

El mayor factor predisponente para que ocurra este desplazamiento es la presencia de una delgada o perforada cortical lingual asociada a terceras molares in- 
feriores. Además, una fuerza excesiva o incontrolada, una inapropiada manipulación y una inadecuada evaluación clínica radiográfica, son factores importantes que pueden estar relacionados al desplazamiento de la tercera molar mandibular. ${ }^{12-14}$ Otros autores señalan que existen múltiples factores predisponentes que no se consideran, como: la abertura bucal, la edad del paciente, la forma facial, el uso de aparatología bucal, etc. ${ }^{15}$

$\mathrm{Al}$ examen clínico, los pacientes pueden presentar disminución en la abertura bucal, edema, trismo o molestias al deglutir. ${ }^{1,3,8,12}$

Para obtener la ubicación exacta de la pieza dentaria desplazada las radiografías periapicales, panorámicas y laterales como exámenes complementarios para este tipo de casos son inadecuados porque nos muestran imágenes en dos dimensiones. La tomografía computarizada es la mejor ayuda para la ubicación de la pieza dental desplazada a los tejidos peri bucales al mostrarnos imágenes en tres dimensiones (sagital, frontal y coronal) del espacio, dichas imágenes tomográficas deben ser obtenidas antes de intentar realizar una segunda intervención quirúrgica. ${ }^{8}$

Dentro del tratamiento del desplazamiento de la tercera molar al espacio faríngeo lateral, algunos autores prefieren acceder al diente en el mismo momento en que se produce el desplazamiento, pues consideran que posponer la cirugía puede incrementar el riesgo de infección y reacción a cuerpo extraño. ${ }^{16} \mathrm{Sin}$ embargo, otros autores refieren que someter a un paciente que lleva un tiempo prolongado en una fallida operación a un nuevo estrés quirúrgico, puede resultar poco prudente y la espera de varias semanas facilitaría la inmovilización del diente por el tejido fibroso que lo rodea, ayudando a su exéresis. ${ }^{17}$

El propósito de este artículo es reportar un caso de desplazamiento de tercera molar mandibular al espacio faríngeo lateral durante la intervención quirúrgica realizada por un odontólogo general.

\section{Reporte de Caso}

Paciente femenina de 21 años de edad, sin enfermedad sistémica ni antecedentes patológicos personales. Acude a odontólogo general para que le realicen la exodoncia de la pieza 3,8 .

El profesional tratante le informó que la exodoncia se había complicado, la pieza 3,8 se había desplazado a los tejidos blandos y había que realizar algunos controles. La paciente acudió a controles por un periodo de 5 semanas y como el profesional tratante no mostraba interés en su caso, acudió a otro profesional (Odontóloga general) quien le indicó radiografía panorámica (Fig. 1) y la derivó al Servicio de Medicina Oral y Cirugía Máxilo Facial del Departamento de Estomatología del Hospital Central FAP.

\section{Plan de trabajo para el diagnóstico}

\section{Examen clínico.}

Exámenes complementarios: radiografía panorámica, tomografía computarizada.

\section{Resultados del plan de trabajo}

La paciente se presentó a la consulta asintomática, pero refiere haberse operado la "muela del juicio" hace, aproximadamente, dos meses en un consultorio particular, la cual fue realizada por un odontólogo general. No se observó algún signo que pueda brindar mayor información al diagnóstico.

En la radiografía panorámica, se observó pieza 3,8 en posición invertida fuera de su alveolo y presencia de imagen radiopaca a nivel de la corona de la pieza 2,8 compatible con supernumerario, el cual impide su erupción.

Se indicó tomografía computarizada (TC) la cual permitió determinar la presencia de la pieza 3,8 en el espacio faríngeo lateral (Fig. 2 y 3). La ubicación fue establecida a $2 \mathrm{~cm}$ de la cara interna de la rama ascendente de la mandíbula, a nivel de la espina de spix y en posición invertida.

\section{Tratamiento}

Remoción de la pieza dental 3,8 con abordaje intraoral

La intervención quirúrgica se realizó con anestesia local (lidocaína al $2 \%$ con epinefrina 1:100 000) se realizó incisión intrasulcar por lingual desde distal de la pieza 3,7 continuando por el reborde alveolar, borde anterior de la mandíbula, hasta la apófisis coronoides, se decoló el colgajo, se realizó disección roma y la pieza 3,8 fue hallada en posición invertida, prensada y extraída con pinza hemostática (Fig. 4). Se realizó la sutura por planos con hilo vicryl (3/0).
Se indicó antibioticoterapia (Clindamicina $300 \mathrm{mg} \mathrm{V}$. O. C/8h por 05 días) y analgésicos (Ketorolaco $10 \mathrm{mg} \mathrm{V}$. O. $\mathrm{C} / 8 \mathrm{~h}$ por 03 días). El post operatorio transcurrió sin novedad, se retiró la sutura a los siete días y se indicó radiografía panorámica de control (Fig. 6).

\section{Discusión}

El desplazamiento de terceras molares inferiores hacia el espacio faríngeo lateral es considerado dentro de los accidentes pocos frecuentes, tras la exodon-

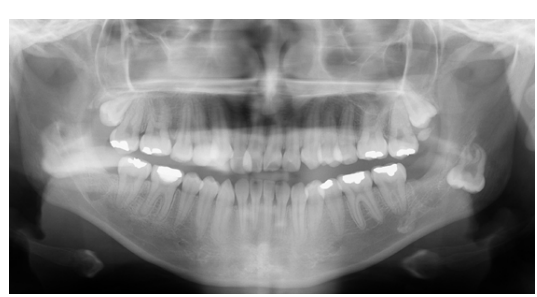

Fig 1. Radiografía Panorámica donde se observa la pieza 3,8 invertida y fuera de su alveolo.

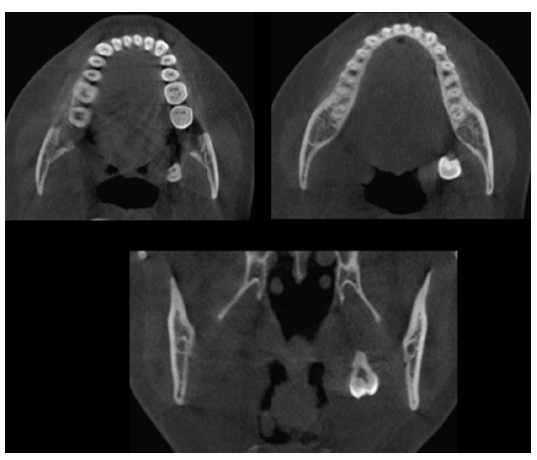

Fig 2. Cortes Tomográficos Axiales y Coronal, pieza 3,8 en espacio faríngeo lateral izquierdo.

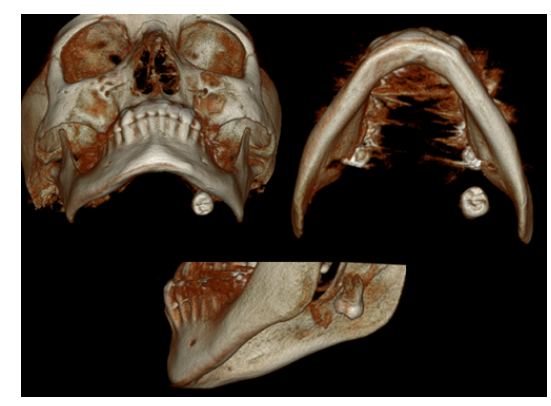

Fig 3. Tomografía con Reconstrucción 3D, pieza 3,8 desplazada al espacio faríngeo lateral izquierdo.

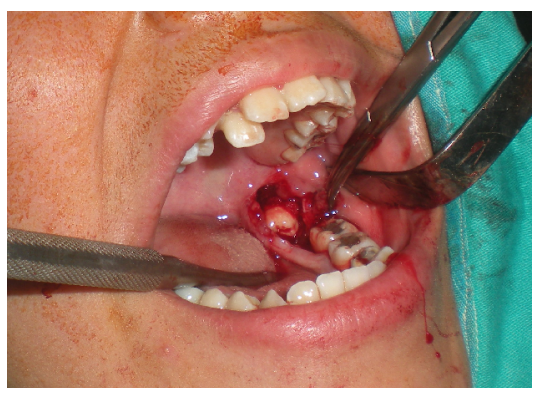

Fig 4. Exodoncia de pieza 3,8 del espacio faríngeo lateral izquierdo. 


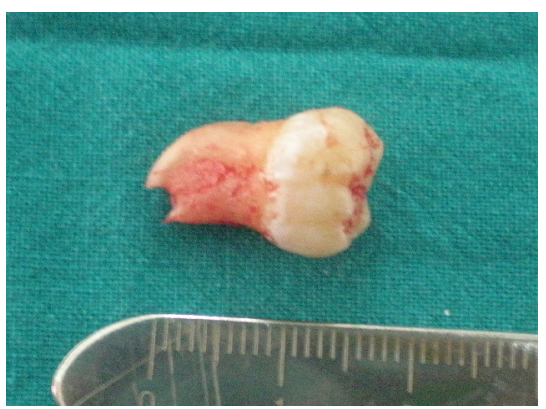

Fig 5. Pieza 3,8 luego de la intervención quirúrgica.

cia de terceras molares como lo refieren algunos autores. ${ }^{15,6}$ En el Perú, no existe ningún reporte de caso con referencia a este tema.

La paciente se encontraba asintomática, solo había la preocupación de una posible secuela por el fracaso de la exodoncia. En otros reportes, los pacientes presentaron disminución de la abertura bucal, edema, trismo y disfagia. ${ }^{1,3,8,12}$

En la radiografía panorámica, se observó la presencia de la pieza ${ }^{3,8}$ fuera del alveolo, en posición invertida a la altura de la rama mandibular izquierda. Esta radiografía no es recomendable como medio auxiliar para la ubicación final, porque no muestra en el espacio la localización exacta. ${ }^{8}$

La ubicación exacta final se obtuvo mediante la tomografía computarizada, que es el medio de diagnóstico por imágenes más indicado y utilizado en este tipo de casos. ${ }^{1,3,8,12,13}$

Los reportes que sugieren la remoción inmediata de la pieza desplazada son escasos $^{16}$. En el presente reporte, la paciente acudió luego de dos meses de transcurrido la complicación de exodoncia de la pieza ${ }^{3,8}$ (desplazamiento al espacio faríngeo lateral izquierdo) y se realizó la exodoncia debido al tiempo transcurrido. La remoción quirúrgica fue facilitada porque la pieza dentaria se encontraba rodeada por tejido fibroso, como lo refieren algunos autores ${ }^{1}$. En el caso que la remoción se hubiera hecho en un tiempo muy cercano a la complicación es muy probable que dicho tejido fibroso no se hubiera desarrollado, dificultando la remoción de la pieza dentaria.

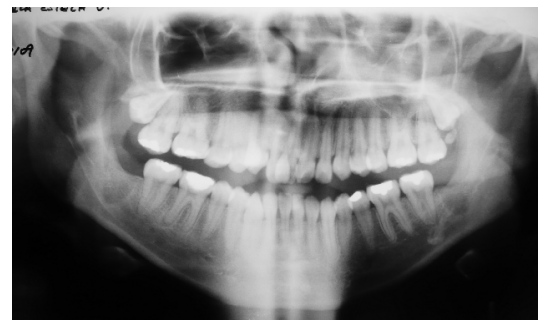

Fig 6. Radiografía panorámica post quirúrgico.

\section{Conclusión}

El Cirujano Buco Máxilo Facial es el apoyo que requiere el Odontólogo General en los tratamientos quirúrgicos de la especialidad y en el manejo de las complicaciones.

Los cirujanos dentistas deben realizar un cuidadoso examen radiográfico antes y después de la remoción de las terceras molares, especialmente cuando el tratamiento quirúrgico presentó complicaciones en el trans operatorio.

Los cirujanos dentistas deben considerar la posibilidad de algún accidente en el trans operatorio, dentro de estos, el desplazamiento de la pieza dentaria o fragmento de diente a los espacio peri bucales. Dichas complicaciones pueden repercutir en el cirujano dentista en problemas médico - legales.

Los pacientes que requieren intervención quirúrgica y en la valoración inicial son considerados moderados o de alta complejidad, deben ser derivados al especialista para su tratamiento y de esta manera evitar posibles complicaciones que afecten la integridad del paciente.

\section{Referencias Bibliográficas}

1. Algozaín Y, Viñas G. Desplazamiento accidental hacia el espacio parafaríngeo de un fragmento de un tercer molar inferior retenido. Revista Cubana de Estomatología. 2008; 45(1).

2. Gay C, Berini L. Tratado de Cirugía Bucal, Tomo I. Madrid: Ergon; 2004. p. 309 - 39.

3. Sacot N, Ferrería J. Mala praxis en la cirugía del tercer molar retenido. Rev Fac Odontol B Aires. 1996; 16 (42): $23-7$.

4. Morejón F, López H, Morejón T, Corbo M. Presentación de un estudio en 680 pacientes operados de terceros molares retenidos. Rev Cubana de Estomatol. 2000; 37(2): 102-5.

5. Esen E, Barlas L, Caayat M. Accidental displacement of an impacted mandibular third molar into the lateral pharyngeal space. Journal of Oral and Maxillofacial Surgery. 2000; 58(1): $96-7$.

6. Medeiros N, Gaffrée G. Accidental Displacement of Inferior Third Molar Into the Lateral Pharyngeal Space: Case Report. Journal of Oral and Maxillofacial Surgery. 2008; 66(3): $578-80$
7. Simoes F, Santos G, Olandoski M, Guariza O. Analysis of accidents and complications in surgical removal of impacted mandibular third molars occured in Curitiba. RSBO. 2005; 32(2): 43 - 48.

8. Kamburoglu, Ilker C. Erdem. Accidental displacement of a mandibular third molar crown into the parapharyngea 1 space during extraction. Oral Surgery. 2008; 1(2): $114-16$.

9. Choi Y, Jee Y, Song H. Displacement of a lower third molar into the lateral pharyngeal space. Korean Assoc Oral Maxillofac Surg. 2004; 30(6): 551-3.

10. Durmus E, Dolanmaz D, Kucukkolbsi H, Mutlu N. Accidental displacement of impacted maxillary and mandibular third molars. Quintessence Int. 2004; 35(5): 375.

11. Tamashiro T, Arias P. Iatropatogenia en la extracción de retenciones dentarias. Revista de la Asociación Dental Mexicana. 2003; 60(1): 29 -33 .

12. Ortakoglu K, Okcu K, Karasu H, Günaydin Y. Accidental displacement of impacted third molar into lateral pharyngeal space. Turk J Med Sci. 2002; 32: 431 - 33.

13. Moncada P, Del Aguila Q, Uchima K, Castillo S. Quiste dentígero asociado con tercer molar ectópico en el seno maxilar. Vis Dent. 2009; 12(2): $539-45$.

14. Ozyuvaci H, Firat D, Tanyel C. Accidental displacement of a mandibular third molar: A case report. Quintessence Int. 2003; 34(4):27880 .

15. Ertas U, Selim M, Tozoglu S. Accidental third molar displacement into the lateral pharyngeal space. J Oral Maxillofac Surg. 2002; 60: $1217-18$

16. Manotas I. Exodoncia del Tercer Molar Incluido: Factores que determinan su complejidad. Revista de la Facultad de Ciencias de la Salud - UniMagdalena. 2008; 5(2): $141-7$

17. Pascualini D, Erniani F, Coscia D, Pomatto E, Mela F. Third molar extraction. Minerva Stomatol. 2002; 51: $411-30$.

Fecha de recepción: 14-4-10

Fecha de aprobación: 10-06-10 